\title{
Factors Associated With Treatment Satisfaction After Robot-assisted Radical Prostatectomy
}

\author{
TOMOMI NAKAGAWA, YOSHIFUMI KADONO, RENATO NAITO, HIROAKI IWAMOTO, \\ HIROSHI YAEGASHI, MASASHI IIJIMA, SHOHEI KAWAGUCHI, TAKAHIRO NOHARA, \\ KAZUYOSHI SHIGEHARA, KOUJI IZUMI and ATSUSHI MIZOKAMI \\ Department of Integrative Cancer Therapy and Urology, \\ Kanazawa University Graduate School of Medical Science, Kanazawa, Japan
}

\begin{abstract}
Background/Aim: To evaluate the chronological changes in health-related quality of life and treatment satisfaction after robot-assisted radical prostatectomy (RARP). Patients and Methods: A total of 196 patients were included, and treatment satisfaction was evaluated using the Expanded Prostate Cancer Index Composite (EPIC) score before and at 1, 3, 6, and 12 months after RARP. Results: At 12 months after RARP, $64.8 \%$ of patients were satisfied. On the contrary, $4.6 \%$ of patients were dissatisfied at 12 months after RARP. In a multivariate analysis, only urinary bother of EPIC was significantly associated with satisfaction at 12 months after RARP ( $p=0.025$, odds ratio=1.029). Conclusion: Treatment satisfaction with RARP was generally acceptable from 1 to 12 months after surgery and did not change over time. Urinary bother was associated with satisfaction at 12 months after RARP. Compared with the objective 24-hour pad test, questionnaires answered subjectively were more associated with satisfaction.
\end{abstract}

The incidence of prostate cancer has been increasing worldwide; however, the mortality rate is not extremely high (1). Because such a condition can be detected at an early stage via screening and the proportion of patients with localized prostate cancer is high, most patients undergoing local treatment live for a long time after treatment (2). Radical prostatectomy (RP) is a treatment option for localized prostate cancer. In particular, robot-assisted RP

Correspondence to: Yoshifumi Kadono, MD, Ph.D., Department of Integrative Cancer Therapy and Urology, Kanazawa University Graduate School of Medical Science, 13-1 Takara-machi, Kanazawa, Ishikawa 920-8640, Japan. Tel: +81 762652393, Fax: +81 762344263I, e-mail: yskadono@yahoo.co.jp

Key Words: Treatment satisfaction, robotic prostatectomy, Expanded Prostate Cancer Index Composite, International Consultation on Incontinence Questionnaire Short Form, 24-hour pad test.
(RARP) is being increasingly used worldwide due to its reduced learning curve as a result of technical advances, including three-dimensional visualization and use of dedicated robotic instruments (3); therefore, postoperative health-related quality of life (HRQOL) after RARP must be considered.

Urinary incontinence (UI) and erectile dysfunction (ED) are the major problems after RP; thus, specific questionnaires, such as the International Consultation on Incontinence Questionnaire Short Form (ICIQ-SF) for UI (4) and the 5-item version of the International Continence Society (IIEF-5) for erectile dysfunction (5), are used for evaluations. Considering these main problems after RP, prostate cancer-specific HRQOLs have been evaluated using the UCLA Prostate Cancer Index (6) and Expanded Prostate Cancer Index Composite (EPIC) questionnaire (7). EPIC is a wellestablished instrument used for assessing HRQOL after prostate cancer treatment. Moreover, it has been validated and translated into various languages, including Japanese (8). Such an instrument has a questionnaire for treatment satisfaction. In this study, EPIC was used to evaluate chronological changes in HRQOL and treatment satisfaction after RARP. Furthermore, several studies about patient satisfaction have shown that factors such as urinary and sexual dysfunction are associated with post-treatment satisfaction (9-12). Moreover, in this study, factors affecting treatment satisfaction were evaluated using the EPIC score, ICIQ-SF score, 24-hour pad test, and perioperative parameters.

\section{Patients and Methods}

Study population. The data of patients who underwent RARP at our hospital from March 2012 to December 2016 and were followed-up 12 months after surgery were analyzed. The patients were required to complete the EPIC questionnaire before and after surgery, and those with inadequate clinical data or incomplete questionnaires were excluded. The study protocol was approved by the Institution's Ethics Committee [approval number: 2011-100 (1174)], and informed consent was obtained from each patient. 
The patients started pelvic floor exercises 1 month after surgery, and such exercises were continued until urinary continence was achieved (13). Prostate-specific antigen (PSA) levels were measured before treatment, and the Gleason score was determined during prostate biopsy. For a subjective evaluation, the Japanese version of the ICIQ-SF (14) and questionnaires regarding daily pad use were administered to the patients; the answers of the 24-hour pad test were obtained for objective evaluation. The latter was performed three times. Firstly, we provided patients with a platform scale and instructed them to weigh each pad before and after use; secondly, we calculated the difference between the two weights. The overall 24-hour pad test results were defined as the average increase in pad weight over the three tests (15). The 24-hour pad tests were performed before and 12 months after RARP. For all patients, RARP was performed using a conventional transperitoneal approach with double-layered posterior reconstruction, as described previously (16).

Measurement of HRQOL. The patients were routinely scheduled to visit our hospital before and at 1, 3, 6, and 12 months after RARP. During each visit, they were instructed to complete the Japanese version of the EPIC and ICIQ-SF questionnaires and to write down their answer regarding pad usage per day. The EPIC questionnaire comprises 50 questions and is divided into four domains: urinary, bowel, sexual, and hormone, each composed of function and bother subscales. Furthermore, with regard to the urinary domain, function and bother can be integrated to score two symptoms of urinary incontinence and urinary irritation/obstruction (7). The summary and subscale scores of the four domains were calculated and converted to a scale of $0-100$, with higher scores representing better HRQOL (7). Overall treatment satisfaction was determined using a single question: "Overall, how satisfied are you with the treatment you received for your prostate cancer?" Overall satisfaction was measured using five scales ranging from "extremely dissatisfied" to "extremely satisfied." Patients who were satisfied or extremely satisfied with their treatment for prostate cancer were classified as satisfied. We adopted the Japanese version of EPIC (iHope International, Kyoto, Japan) (8).

Statistical analysis. Categorical variables were used to calculate the incidence and percentage of each factor, and all continuous variables are presented as medians with range. The Mann-Whitney $U$-test was used to compare hormone function and bother of patients with/without androgen deprivation therapy (ADT). The correlations between each variable were calculated using Spearman's rank correlation. For each domain, the EPIC subscales before RARP and at 1,3,6, and 12 months after RARP were compared and analyzed using paired $t$-test. Univariate and multivariate logistic regression analyses were performed to identify factors associated with overall satisfaction at 12 months after RARP. All data analyses were performed using the Statistical Package for the Social Sciences software for Windows (SPSS Inc., Chicago, IL, USA), and those with $p<0.05$ were considered statistically significant.

\section{Results}

A total of 203 consecutive patients who underwent RARP were included; however, seven patients did not complete all the questionnaires. Therefore, 196 patients were finally evaluated. The characteristics of the patients, perioperative
Table I. Demographic characteristics of the study population $(N=196)$.

\begin{tabular}{|c|c|}
\hline Variable & Value \\
\hline \multicolumn{2}{|l|}{ Age, years } \\
\hline Median (range) & $66.0(50-76)$ \\
\hline \multicolumn{2}{|c|}{ Body mass index, $\mathrm{kg} / \mathrm{m}^{2}$} \\
\hline Median (range) & $23.4(17.4-31.1)$ \\
\hline \multicolumn{2}{|c|}{ Initial PSA level, ng/ml } \\
\hline Median (range) & $6.34(1.8-36.7)$ \\
\hline \multicolumn{2}{|c|}{ Biopsy Gleason score, $\mathrm{n}(\%)$} \\
\hline 6 & $68(34.7 \%)$ \\
\hline 7 & $85(43.4 \%)$ \\
\hline 8 & $32(16.3 \%)$ \\
\hline $9-10$ & $11(5.6 \%)$ \\
\hline \multicolumn{2}{|c|}{ Clinical T stage, $\mathrm{n}(\%)$} \\
\hline $\mathrm{T} 1$ & $43(21.9 \%)$ \\
\hline $\mathrm{T} 2$ & $144(73.5 \%)$ \\
\hline $\mathrm{T} 3$ & $9(4.6 \%)$ \\
\hline \multicolumn{2}{|c|}{ D'Amico risk, n (\%) } \\
\hline Low & $58(29.6 \%)$ \\
\hline Intermediate & $76(38.8 \%)$ \\
\hline High & $62(31.6 \%)$ \\
\hline \multicolumn{2}{|l|}{ NADT, n (\%) } \\
\hline No & $164(83.7 \%)$ \\
\hline Yes & $32(16.3 \%)$ \\
\hline \multicolumn{2}{|c|}{ Preoperative pad use/day, n (\%) } \\
\hline 0 & $194(99.0 \%)$ \\
\hline 1 & $2(1.0 \%)$ \\
\hline \multicolumn{2}{|c|}{ Preoperative 24-hour pad test, g } \\
\hline Median (range) & $0(0-31)$ \\
\hline \multicolumn{2}{|c|}{ Preoperative ICIQ-SF score } \\
\hline Median (range) & $0(0-11)$ \\
\hline \multicolumn{2}{|c|}{ Nerve-sparing procedure } \\
\hline None & $31(15.8 \%)$ \\
\hline Unilateral & $128(65.3 \%)$ \\
\hline Bilateral & $37(18.9 \%)$ \\
\hline \multicolumn{2}{|l|}{ Surgical time, $\min$} \\
\hline Median (range) & $237.5(138-398)$ \\
\hline \multicolumn{2}{|l|}{ Console time, $\min$} \\
\hline Median (range) & $185(102-352)$ \\
\hline \multicolumn{2}{|c|}{ Removed prostate weight, $g$} \\
\hline Median (range) & $38.0(15-87)$ \\
\hline \multicolumn{2}{|c|}{ Pad use/day at 12 months, $\mathrm{n}(\%)$} \\
\hline 0 & $128(65.3 \%)$ \\
\hline 1 security liner & $28(14.3 \%)$ \\
\hline 1 & $24(12.2 \%)$ \\
\hline$>2$ & $16(8.2 \%)$ \\
\hline \multicolumn{2}{|c|}{ 24-h pad test at 12 months, g } \\
\hline Median (range) & $1(0-192)$ \\
\hline \multicolumn{2}{|c|}{ PSA at 12 months, $\mathrm{n}(\%)$} \\
\hline Recurrence & $12(6.1 \%)$ \\
\hline
\end{tabular}

PSA: Prostate-specific antigen; NADT: neoadjuvant androgen deprivation therapy; ICIQ-SF: International Consultation on Incontinence Questionnaire-Short Form.

parameters, and 24-hour pad test result are summarized in Table I. None of the patients had RARP complications greater than grade III according to the Clavien classification (17). Of the 12 patients with PSA recurrence at 12 months 
A
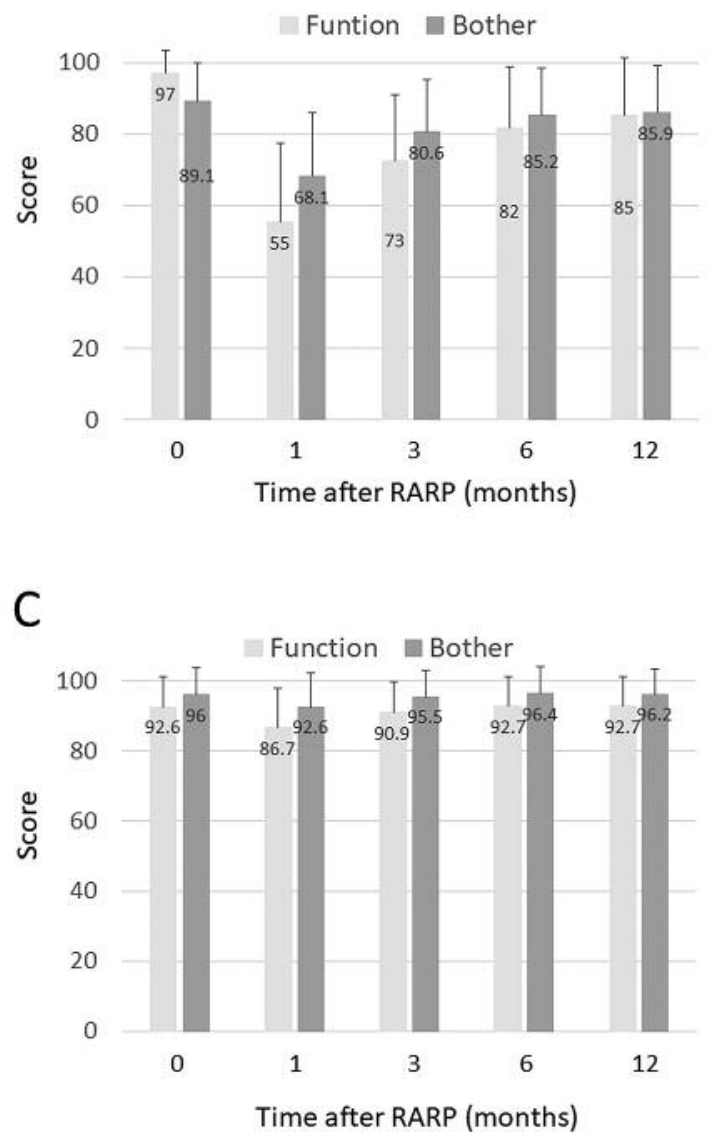

$\mathrm{E}$

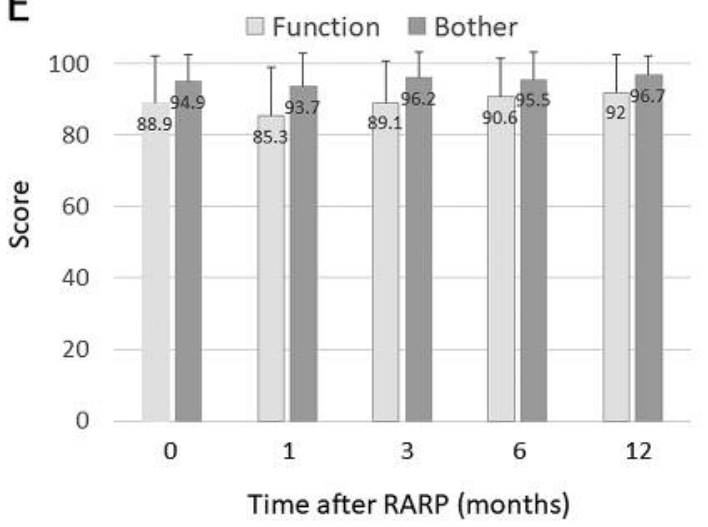

after RARP, three and seven received salvage ADT 3-6 and 6-12 months after RARP, respectively, and one patient underwent radiation therapy to the pelvic space 9 months after RARP. Chronological changes in each component of the EPIC score are shown in Figure 1. Urinary function, bother and incontinence worsened after RARP, and although
B
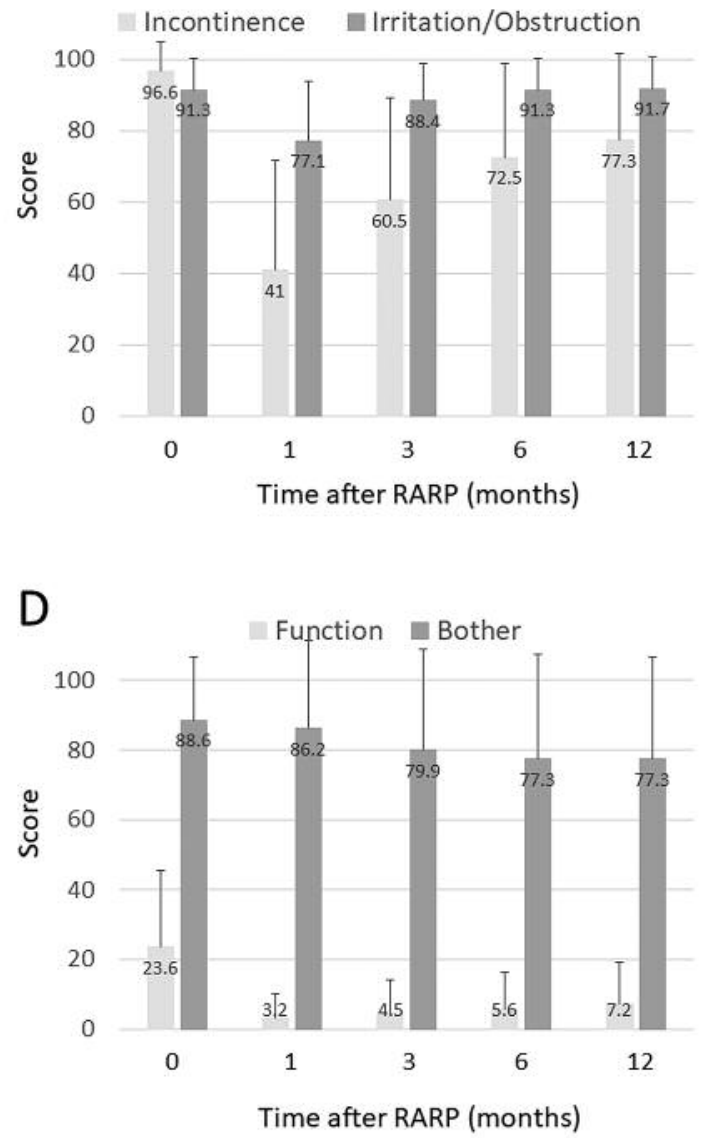

Figure 1. Chronological changes in mean scores for each domain of the Expanded Prostate Cancer Index Composite after robot-assisted radical prostatectomy (RARP). A: Urinary function and bother. B: Urinary incontinence and irritation/obstruction. $C$ : Bowel function and bother. D: Sexual function and bother. E: Hormonal function and bother.

the scores gradually recovered, they did not return to the preoperative level until 12 months after RARP (Figure 1A and B). Urinary irritation/obstruction, bowel function and bowel bother worsened 1 month after RARP. However, the scores gradually returned to the preoperative level (Figure $1 \mathrm{~B}$ and $\mathrm{C})$. The sexual function score was low before RARP, 


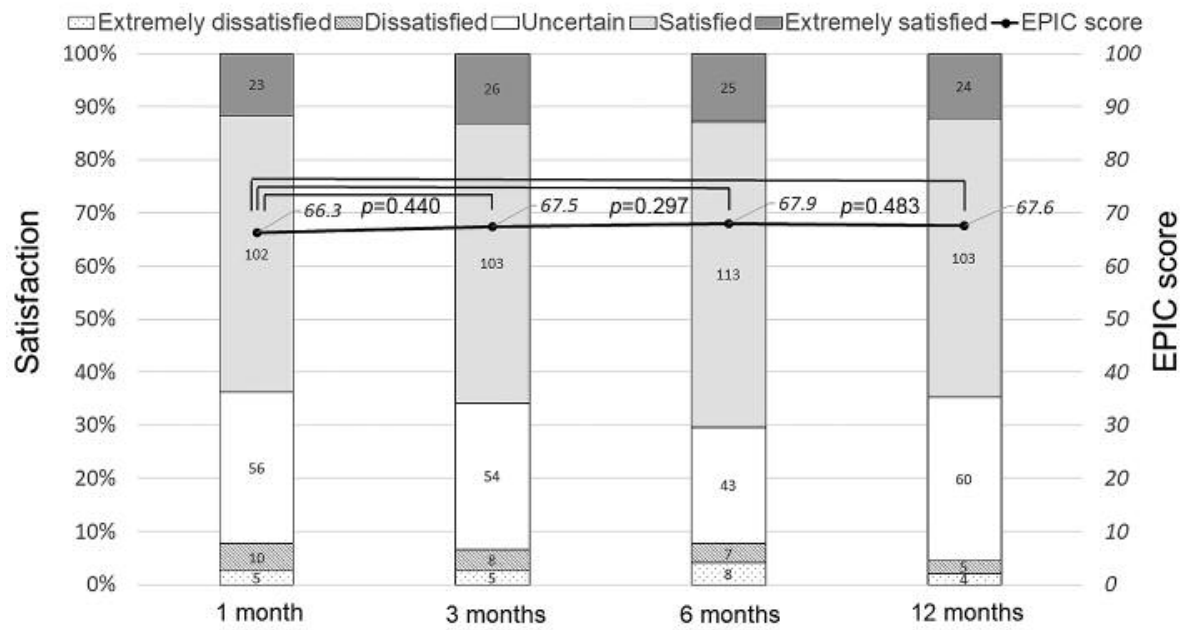

Figure 2. Chronological changes in the mean score for overall satisfaction of the Expanded Prostate Cancer Index Composite (EPIC) after robotassisted radical prostatectomy and the proportion for each answer.

and continually worsened after RARP (Figure 1D). Moreover, the sexual bother score was low, but not as low as the sexual function score, and it further decreased after RARP. However, the decrease was not as low as that of the sexual function score (Figure 1D). The hormone function and bother scores worsened 1 month after RARP but had improved significantly 12 months after RARP (Figure $1 \mathrm{E}$ ). A total of 32 patients received neoadjuvant ADT. The mean scores of hormone function for non-neoadjuvant ADT and neoadjuvant ADT groups were 90.5 and 80.7 , respectively $(p<0.001)$, and the mean scores of HB for non-neoadjuvant ADT and neoadjuvant ADT were 95.6 and 91.5, respectively $(p<0.001)$. Ten patients received salvage ADT after PSA recurrence at 12 months after RARP. The mean scores of hormone function for non-salvage ADT and salvage ADT groups were 92.5 and $81.5(p<0.001)$, respectively, and the mean scores of hormone bother for non-salvage ADT and salvage ADT were 97.0 and $91.7(p<0.001)$, respectively.

The chronological changes in overall satisfaction after RARP are shown in Figure 2, and no significant difference was found over time. At 12 months after RARP, approximately $64.8 \%$ of the patients were satisfied, including those who selected "Extremely satisfied" and "Satisfied." Univariate and multivariate logistic regression analyses were performed to identify factors associated with the selection of "Extremely satisfied" or "Satisfied" 12 months after RARP (Table II). In the multivariate analysis, the factors with $p<0.1$ in the univariate analysis were selected; however, the factor with the lowest $\mathrm{p}$-value was selected among the factors with high correlation coefficient. The correlation coefficients of urinary function with bother, and with ICIQ-SF total score, and of urinary bother with ICIQ total score were high $(\mathrm{r}=0.572,-0.843$, and -0.658 , respectively; $p<0.001)$. Hormone function and bother had a high correlation coefficient $(\mathrm{r}=0.698, p<0.001)$. In the multivariate analysis, urinary bother was significantly associated only with satisfaction at 12 months after RARP. On the contrary, at 12 months after RARP, $4.6 \%$ of the patients were dissatisfied, including those who selected "Dissatisfied" or "Extremely dissatisfied." The factors affecting dissatisfaction were analyzed; however, no significant factors were identified (data not shown).

\section{Discussion}

The present study showed the chronological changes in HRQOL and treatment satisfaction before and after RALP using EPIC and assessed the factors affecting treatment satisfaction. To the best of our knowledge, this is the first study to evaluate the factors affecting treatment satisfaction using multiple items, including each EPIC score, ICIQ-SF score, perioperative parameters, and objective 24-hour pad test result. In addition, our cohort only included Japanese patients.

The chronological changes in individual urinary and bowel components of EPIC in this study were similar to those of previous reports $(11,18-21)$. The preoperative sexual function score of our cohort was about one-third to half of those of other reports, and it significantly decreased after RARP. The preoperative sexual bother score was almost similar to that of other reports, and a minimal decrease in sexual bother score was observed after RARP. However, it 
Table II. Univariate and multivariate logistic regression analyses to identify factors associated with overall satisfaction 12 months after robotassisted radical prostatectomy.

\begin{tabular}{|c|c|c|c|}
\hline \multirow[b]{2}{*}{ Factor } & \multirow{2}{*}{$\begin{array}{c}\text { Univariate analysis } \\
p \text {-Value }\end{array}$} & \multicolumn{2}{|c|}{ Multivariate analysis } \\
\hline & & OR $(95 \% \mathrm{CI})$ & $p$-Value \\
\hline Age, years & 0.648 & & \\
\hline Body mass index, $\mathrm{kg} / \mathrm{m}^{2}$ & 0.794 & & \\
\hline Initial PSA level, ng/ml & 0.502 & & \\
\hline \multicolumn{4}{|l|}{ D'Amico risk } \\
\hline Low & Reference & & \\
\hline Intermediate & 0.937 & & \\
\hline High & 0.771 & & \\
\hline \multicolumn{4}{|l|}{ Nerve-sparing procedure } \\
\hline None & Reference & & \\
\hline Unilateral & 0.965 & & \\
\hline Bilateral & 0.128 & & \\
\hline Weight of the removed prostate, $g$ & 0.741 & & \\
\hline ICIQ-SF total score at 12 months & 0.005 & & \\
\hline 24-h pad test at 12 months, $\mathrm{g}$ & 0.266 & & \\
\hline \multicolumn{4}{|l|}{ PSA recurrence at 12 months } \\
\hline No & Reference & Reference & \\
\hline Yes & 0.094 & $0.470(0.135-1.637)$ & 0.236 \\
\hline \multicolumn{4}{|l|}{ EPIC domain subscale at 12 months } \\
\hline \multicolumn{4}{|l|}{ Urinary } \\
\hline Function & 0.02 & & \\
\hline Bother & 0.003 & $1.029(1.004-1.054)$ & 0.025 \\
\hline \multicolumn{4}{|l|}{ Bowel } \\
\hline Function & 0.048 & $1.021(0.985-1.058)$ & 0.263 \\
\hline Bother & 0.642 & & \\
\hline \multicolumn{4}{|l|}{ Sexual } \\
\hline Function & 0.094 & $1.023(0.992-1.055)$ & 0.152 \\
\hline Bother & 0.277 & & \\
\hline \multicolumn{4}{|l|}{ Hormone } \\
\hline Function & 0.054 & & \\
\hline Bother & 0.045 & $1.013(0.995-1.075)$ & 0.66 \\
\hline
\end{tabular}

CI: Confidence interval; EPIC: Expanded Prostate Cancer Index Composite for Clinical Practice; ICIQ-SF: International Consultation on Incontinence Questionnaire-Short Form; OR: odds ratio; PSA: prostate-specific antigen.

was higher than that of other reports (18-20). Japanese men have reported lower sexual function scores at baseline than American men, and American men are less likely to improve scores for sexual bother after RP than Japanese men (22). Ethnicity may be a contributing factor for sexual function and bother. Approximately $38.6 \%$ of patients experienced fatigue caused by ADT (23); therefore, neoadjuvant and salvage ADT may affect hormone function and bother before and 12 months after RARP. A total of 32 (16.3\%) patients received neoadjuvant ADT, and 12 months after RARP, 10 patients received salvage ADT in this cohort. In this study, the mean hormone function and bother scores for nonneoadjuvant and neoadjuvant ADT groups before RARP were 90.5 and $80.7(p<0.001)$ and 95.6 and $80.5(p=0.007)$, respectively. The mean hormone function scores for nonsalvage ADT and salvage ADT groups at 12 months after RARP were 92.5 and $81.5 \quad(p<0.001)$, respectively.
Moreover, the mean hormone bother scores for non-salvage and salvage ADT groups at 12 months after RARP were 97.0 and 91.7 ( $p=0.063)$, respectively. However, the hormone function and the hormone bother were not significant factors for overall satisfaction 12 months after RARP (Table II).

At 1 month after RARP, $63.7 \%$ of the patients were satisfied with the treatment, including those who selected "Extremely satisfied" or "Satisfied." Moreover, 64.8\% of the patients were satisfied at 12 months after RARP. Chronological changes in overall satisfaction were not observed in this study. Our results for the proportion of patients who were satisfied with treatment and the chronological changes after RARP were practically similar to those of previous reports $(10,11)$. The correlation coefficient of the following combinations was high: urinary function and urinary bother of EPIC, urinary function of EPIC and ICIQ-SF total score, and urinary bother of EPIC 
and ICIQ-SF total score (15); therefore, urinary bother with the lowest $\mathrm{p}$-value in the univariate analysis was adopted in the multivariate analysis to identify factors associated overall satisfaction 12 months after RARP. However, the ICIQ-SF total score, which was adopted in the multivariate analysis, rather than urinary bother, was a significant factor (odds ratio $=0.92,95 \%$ confidence interval $=0.856-0.994 ; p=0.035$ ), and urinary function, rather than urinary bother, had a tendency for association. However, the result was not significant (odds ratio $=0.92,95 \%$ confidence intervaI $=0.999$ $1.038 ; p=0.069)$. ICIQ-SF is a simple questionnaire compared with EPIC; therefore, ICIQ-SF might be convenient to use for the evaluation of urinary incontinence status to assess for satisfaction among patients undergoing RARP (4). In previous reports, only subjective questionnaires were used to evaluate the association between urinary incontinence and treatment satisfaction $(10,11,24$, 25); therefore, the 24-hour pad test was adopted for the objective evaluation of urinary incontinence to assess for treatment satisfaction in this study. Results showed that the 24-hour pad test was significantly associated with ICIQ total score $(\mathrm{r}=0.622, p<0.001)$, urinary function, $(\mathrm{r}=-0.608$, $p<0.001)$, and urinary bother $(\mathrm{r}=-0.425, p<0.001)$. However, the 24-hour pad test was not significantly associated with treatment satisfaction. The results of the 24-hour pad test vary widely and are not always consistent with the subjective evaluation results, such as those obtained using questionnaires or answers regarding daily pad use (15).

Treatment satisfaction depends on subjective feelings; therefore, the subjective evaluation using questionnaires was associated with overall satisfaction after RARP in this study. On the contrary, at 12 months after RARP, approximately $4.6 \%$ of the patients were not satisfied with the treatment, including those who selected "Dissatisfied" or "Extremely dissatisfied." A higher PSA level concern based on preoccupation with PSA was also associated with regret among the long-term survivors of localized prostate cancer (26). The causes of dissatisfaction were analyzed in that study; however, the definite causes were not identified. Overall satisfaction after RARP in Asians was considerably lower than that of Westerners, who were more concerned about sexual function $(10,11,20,22)$. In relation to this, the factors affecting satisfaction or regret after RARP may include not only the outcomes of the treatment but also race, nationality, personality, and expectation of the treatment. A previous report that assessed the independent predictors of satisfaction and regret after retropubic RP and RARP has shown that patients who underwent RARP are more likely to regret and feel dissatisfied possibly due to higher expectations of the outcomes of innovative procedures (24). The lack of informed decision-making is highly associated with regret because treatment for localized prostate cancer is the patient's preference (26). If patients are properly counseled before surgery, they have more realistic expectations. In addition, adequate counseling about urinary and sexual dysfunction and PSA recurrence rates after RARP might contribute to improving posttreatment satisfaction. In addition, perioperative and postoperative adverse events were associated with poorer HRQOL and treatment satisfaction $(25,27)$.

The present study had some limitations. Firstly, the duration of follow-up was not sufficient to evaluate longterm results, and functional outcomes were found to have changed 5 years after surgery in several studies $(9,28,29)$. In addition, some studies have shown that $83 \%$ of patients still prefer re-surgery despite urinary incontinence within 13 years after RP and 53\% of patients with urinary incontinence choose other treatments over 5 years after surgery (30). This indicates that longer follow-up can change satisfaction and its associated factors. Secondly, social background was not considered in the analysis of overall satisfaction after RARP. This was a prospective study conducted on a series of consecutive cases at a single institution; thus, we believe that it is of value. Despite the short follow-up period, the data obtained in this study might be significant as changes in HRQOL are most significant within 1 year after surgery. The findings are also valuable in terms of the consistency and quality of data because the study only included patients who completed the questionnaire at all timepoints. Nonetheless, further multicenter, randomized studies with longer follow-up must be conducted to confirm the results of our study.

\section{Conclusion}

Treatment satisfaction with RARP was generally acceptable from 1 to 12 months after surgery, and did not change over time. The EPIC urinary bother and ICIQ-SF total scores were associated with satisfaction 12 months after RARP. Compared with the objective 24-hour pad test, questionnaires answered subjectively were more associated with satisfaction.

\section{Conflicts of Interest}

All Authors declare that they have no conflicts of interest in regard to this study.

\section{Authors' Contributions}

Tomomi Nakagawa: Data collection, article drafting; Yoshifumi Kadono: Conception and design, data analysis, article revision; Renato Naito: Data collection, article revision; Hiroaki Iwamoto: Data collection, article revision; Hiroshi Yaegashi: Data collection, article revision; Masashi Iijima: Data collection, article drafting; Shohei Kawaguchi: Data analysis, article drafting; Takahiro Nohara: Conception and design, article revision; Kazuyoshi Shigehara: Data analysis, article revision; Kouji Izumi: Data analysis, article revision; Atsushi Mizokami: Conception and design, article revision. 


\section{References}

1 Kimura $\mathrm{T}$ and Egawa $\mathrm{S}$ : Epidemiology of prostate cancer in Asian countries. Int $\mathrm{J}$ Urol 25(6): 524-531, 2018. PMID: 29740894. DOI: $10.1111 /$ iju.13593

2 Hamdy FC, Donovan JL, Lane JA, Mason M, Metcalfe C, Holding P, Davis M, Peters TJ, Turner EL, Martin RM, Oxley J, Robinson M, Staffurth J, Walsh E, Bollina P, Catto J, Doble A, Doherty A, Gillatt D, Kockelbergh R, Kynaston H, Paul A, Powell P, Prescott S, Rosario DJ, Rowe E, Neal DE and Protec TSG: 10-Year outcomes after monitoring, surgery, or radiotherapy for localized prostate cancer. N Engl J Med 375(15): 1415-1424, 2016. PMID: 27626136. DOI: 10.1056/ NEJMoa 1606220

3 Menon M, Tewari A, Peabody JO, Shrivastava A, Kaul S, Bhandari A and Hemal AK: Vattikuti Institute prostatectomy, a technique of robotic radical prostatectomy for management of localized carcinoma of the prostate: Experience of over 1100 cases. Urol Clin North Am 31(4): 701-717, 2004. PMID: 15474597. DOI: 10.1016/j.ucl.2004.06.011

4 Machioka K, Kadono Y, Naito R, Nakashima K, Iijima M, Kawaguchi S, Shigehara K, Nohara T, Izumi K and Mizokami A: Evaluating urinary incontinence before and after radical prostatectomy using the International Consultation on Incontinence Questionnaire-Short Form. Neurourol Urodyn 38(2): 726-733, 2019. PMID: 30576037. DOI: 10.1002/nau.23907

5 Donovan JL, Peters TJ, Abrams P, Brookes ST, de aa Rosette JJ and Schafer W: Scoring the short form ICSMALESF questionnaire. International Continence Society. J Urol 164(6): 1948-1955, 2000. PMID: 11061889.

6 Litwin MS, Hays RD, Fink A, Ganz PA, Leake B and Brook RH: The UCLA prostate cancer index: Development, reliability, and validity of a health-related quality of life measure. Med Care 36(7): 1002-1012, 1998. PMID: 9674618. DOI: 10.1097/0000 5650-199807000-00007

7 Wei JT, Dunn RL, Litwin MS, Sandler HM and Sanda MG: Development and validation of the expanded prostate cancer index composite (EPIC) for comprehensive assessment of health-related quality of life in men with prostate cancer. Urology 56(6): 899-905, 2000. PMID: 11113727. DOI: 10.1016/s0090-4295(00)00858-x

8 Takegami M, Suzukamo Y, Sanda MG, Kamoto T, Namiki S, Arai Y, Ogawa O, Fukuhara S and Kakehi Y: The Japanese translation and cultural adaptation of expanded prostate cancer index composite (EPIC). Nihon Hinyokika Gakkai Zasshi 96(7): $657-$ 669, 2005. PMID: 16363651. DOI: 10.5980/jpnjurol1989.96.657

9 Penson DF, McLerran D, Feng Z, Li L, Albertsen PC, Gilliland FD, Hamilton A, Hoffman RM, Stephenson RA, Potosky AL and Stanford JL: 5-Year urinary and sexual outcomes after radical prostatectomy: Results from the prostate cancer outcomes study. J Urol 173(5): 1701-1705, 2005. PMID: 15821561. DOI: 10.1097/01.ju.0000154637.38262.3a

$10 \mathrm{Kim}$ JH, Ha YS, Jeong SJ, Kim S, Kim WJ, Jang TL and Kim IY: Factors related to patient-perceived satisfaction after robotassisted radical prostatectomy based on the Expanded Prostate Cancer Index Composite survey. Prostate Cancer Prostatic Dis 16(4): 341-345, 2013. PMID: 23917307. DOI: 10.1038/pcan. 2013.24

11 Pak S, Kim M and Ahn H: Changes in health-related quality of life after radical prostatectomy for prostate cancer: A longitudinal cohort study in Korea. Investig Clin Urol 59(5): 313-320, 2018. PMID: 30182076. DOI: 10.4111/icu.2018. 59.5.313

12 Wagner W, Bolling T, Hambruegge C, Hartlapp J and Krukemeyer MG: Patients' satisfaction with different modalities of prostate cancer therapy - a retrospective survey among 634 patients. Anticancer Res 31(11): 3903-3908, 2011. PMID: 22110217.

13 Marchiori D, Bertaccini A, Manferrari F, Ferri C and Martorana G: Pelvic floor rehabilitation for continence recovery after radical prostatectomy: Role of a personal training re-educational program. Anticancer Res 30(2): 553-556, 2010. PMID: 20332469.

14 Gotoh M, Homma Y, Funahashi Y, Matsukawa Y and Kato M: Psychometric validation of the Japanese version of the International Consultation on incontinence Questionnaire-Short Form. Int J Urol 16(3): 303-306, 2009. PMID: 19207608. DOI: 10.1111/j.1442-2042.2008.02237.x

15 Kadono Y, Nohara T, Kadomoto S, Nakashima K, Iijima M, Shigehara $\mathrm{K}$, Narimoto $\mathrm{K}$, Izumi $\mathrm{K}$ and Mizokami $\mathrm{A}$ : Investigating urinary conditions prior to robot-assisted radical prostatectomy in search of a desirable method for evaluating post-prostatectomy incontinence. Anticancer Res 36(8): 42934298, 2016. PMID: 27466547.

16 Kadono Y, Ueno S, Iwamoto D, Takezawa Y, Nohara T, Izumi $\mathrm{K}$, Mizokami A and Namiki M: Chronological urodynamic evaluation of changing bladder and urethral functions after robot-assisted radical prostatectomy. Urology 85(6): 1441-1447, 2015. PMID: 25863842. DOI: 10.1016/j.urology.2015.02.029

17 Clavien PA, Barkun J, de Oliveira ML, Vauthey JN, Dindo D, Schulick RD, de Santibanes E, Pekolj J, Slankamenac K, Bassi C, Graf R, Vonlanthen R, Padbury R, Cameron JL and Makuuchi $\mathrm{M}$ : The Clavien-Dindo classification of surgical complications: Five-year experience. Ann Surg 250(2): 187-196, 2009. PMID: 19638912. DOI: 10.1097/SLA.0b013e3181b13ca2

18 Tseng TY, Kuebler HR, Cancel QV, Sun L, Springhart WP, Murphy BC, Albala DM and Dahm P: Prospective health-related quality-of-life assessment in an initial cohort of patients undergoing robotic radical prostatectomy. Urology 68(5): 1061-1066, 2006. PMID: 17113898. DOI: 10.1016/j.urology.2006.06.017

19 Willis DL, Gonzalgo ML, Brotzman M, Feng Z, Trock B and Su LM: Comparison of outcomes between pure laparoscopic vs. robot-assisted laparoscopic radical prostatectomy: A study of comparative effectiveness based upon validated quality of life outcomes. BJU Int 109(6): 898-905, 2012. PMID: 21933328. DOI: $10.1111 /$ j.1464-410X.2011.10551.x

20 Blanchard P, Davis JW, Frank SJ, Kim J, Pettaway CA, Pugh TJ, Pisters LL, Ward JF, Choi S, Chapin BF, Hoffman K, Navai N, Achim M, McGuire SE, Matin SF, Nguyen Q, Mahmood U, Graber WJ, Chen HC, Wang X and Kuban DA: Quality of life after brachytherapy or bilateral nerve-sparing robot-assisted radical prostatectomy for prostate cancer: A prospective cohort. BJU Int 121(4): 540-548, 2018. PMID: 28941030. DOI: 10.1111/bju.14021

21 Wagner AA, Cheng PJ, Carneiro A, Dovirak O, Khosla A, Taylor KN, Crociani CM, McAnally KC, Percy A, Dewey LE, Sanda MG and Chang P: Clinical use of Expanded Prostate Cancer Index Composite for clinical practice to assess patient reported prostate cancer quality of life following robot-assisted radical prostatectomy. J Urol 197(1): 109-114, 2017. PMID: 27475967. DOI: $10.1016 /$ j.juro.2016.07.080 
22 Namiki S, Kwan L, Kagawa-Singer M, Tochigi T, Ioritani N, Terai A, Arai Y and Litwin MS: Sexual function following radical prostatectomy: A prospective longitudinal study of cultural differences between Japanese and American men. Prostate Cancer Prostatic Dis 11(3): 298-302, 2008. PMID: 17909566. DOI: 10.1038/sj.pcan.4501013

23 Wilding S, Downing A, Wright P, Selby P, Watson E, Wagland R, Donnelly DW, Hounsome L, Butcher H, Mason M, Henry A, Gavin A and Glaser AW: Cancer-related symptoms, mental wellbeing, and psychological distress in men diagnosed with prostate cancer treated with androgen deprivation therapy. Qual Life Res 28(10): 2741-2751, 2019. PMID: 31115843. DOI: 10.1007/ s11136-019-02212-x

24 Schroeck FR, Krupski TL, Sun L, Albala DM, Price MM, Polascik TJ, Robertson CN, Tewari AK and Moul JW: Satisfaction and regret after open retropubic or robot-assisted laparoscopic radical prostatectomy. Eur Urol 54(4): 785-793, 2008. PMID: 18585849. DOI: 10.1016/j.eururo.2008.06.063

25 Abraham NE, Makarov DV, Laze J, Stefanovics E, Desai R and Lepor H: Patient centered outcomes in prostate cancer treatment: Predictors of satisfaction up to 2 years after open radical retropubic prostatectomy. J Urol 184(5): 1977-1981, 2010. PMID: 20850836. DOI: 10.1016/j.juro.2010.06.099

26 Hoffman RM, Lo M, Clark JA, Albertsen PC, Barry MJ, Goodman M, Penson DF, Stanford JL, Stroup AM and Hamilton AS: Treatment decision regret among long-term survivors of localized prostate cancer: Results from the prostate cancer outcomes study. J Clin Oncol 35(20): 2306-2314, 2017. PMID: 28493812. DOI: 10.1200/JCO.2016.70.6317
27 Loppenberg B, von Bodman C, Brock M, Roghmann F, Noldus $\mathrm{J}$ and Palisaar RJ: Effect of perioperative complications and functional outcomes on health-related quality of life after radical prostatectomy. Qual Life Res 23(10): 2743-2756, 2014. PMID: 24902939. DOI: $10.1007 / \mathrm{s} 11136-014-0729-1$

28 Parker WR, Wang R, He C and Wood DP Jr.: Five year expanded prostate cancer index composite-based quality of life outcomes after prostatectomy for localized prostate cancer. BJU Int 107(4): 585-590, 2011. PMID: 20804482. DOI: 10.1111/ j.1464-410X.2010.09579.x

29 Namiki S, Ishidoya S, Ito A, Kawamura S, Tochigi T, Saito S and Arai Y: Quality of life after radical prostatectomy in japanese men: A 5-year follow up study. Int J Urol 16(1): 75-81, 2009. PMID: 19054169. DOI: 10.1111/j.1442-2042.2008.02197.x

30 Herr HW: Quality of life in prostate cancer patients. CA Cancer J Clin 47(4): 207-217, 1997. PMID: 9242169. DOI: 10.3322/ canjclin.47.4.207 